\title{
Determination of dynamic elastic moduli and shear moduli of aged wood by means of ultrasonic devices
}

\author{
Katalin Kránitz • Markus Deublein • Peter Niemz
}

Received: 11 May 2012/ Accepted: 23 May 2013/Published online: 27 June 2013

(C) RILEM 2013

\begin{abstract}
Due to ecological and environmental factors, re-using aged wood is becoming more and more important, also in applications where mechanical strength plays a central role. The aim of this study was to examine specific mechanical parameters of naturally aged and dried wood and to better understand the influence of aging on the elastic behaviour of wood. To this aim, measurements on boards and on small, clear wood specimens were carried out. Ultrasound velocities of longitudinal and, in some cases, of transversal waves were measured to determine dynamic elastic moduli and shear moduli. The measurements were performed on structural timber of aged Norway spruce (aged wood) and compared with specimens of recently cut and kiln dried timber of the same species (recent wood) as a reference with comparable density properties and average annual ring width. The measurements revealed higher values of dynamic elastic modulus for aged wood in the longitudinal and radial directions, but no significant difference was found in the tangential direction or in the shear moduli. It is supposed that the difference is
\end{abstract}

K. Kránitz $(\varangle) \cdot$ P. Niemz

Wood Physics, Institute for Building Materials, ETH

Zurich, Schafmattstrasse 6, HIF, 8093 Zurich, Switzerland

e-mail: kranitzk@ethz.ch

M. Deublein

Institute of Construction and Infrastructure Management, Chair of Infrastructure Management, ETH Zurich, Wolfgang-Pauli-Str. 15, HIL, 8093 Zurich, Switzerland more likely a consequence of variability in densities and the structure parameters (annual ring structure, microfibril angle, growth conditions) rather than a consequence of the wood age. The relation between the dynamic elastic modulus in the longitudinal direction and wood density was nearly the same for aged and recent wood specimens, so with increased prudence, grading methods developed for recent wood can also be applied for aged wood.

Keywords Aged wood - Norway spruce $\cdot$ Dynamic elastic modulus $\cdot$ Shear modulus $\cdot$ Ultrasound velocity

\section{Introduction}

The demand for recycling aged wood has remarkably increased over recent years. The most common option is its utilization as an energy source, but it also can be re-used as raw material for manufactured timber products and its application for furniture construction and interior design is becoming more important as well. For these purposes it is crucial to know the mechanical properties and behaviour of aged wood. In addition, this knowledge is also important for the conservation of cultural heritage.

Aging is understood as the irreversible change of physical and mechanical properties of a material during longer storage or usage. Wood ages over time and deteriorates through environmental influences [44]. Effects of wood destroying organisms, 
photodegradation and weathering or long-term loading are well known and frequently investigated. However, only few references are available regarding structurally sound, naturally aged wood stored in air and in some cases, the results therein are even contradictory (e.g. [23, 41] about shrinkage).

The macroscopic structure of wood appears remarkably stable, unless it is attacked by microorganisms [4], investigations on old samples showed only minor changes in the chemical composition. Hemicelluloses constitute the most degradable part of wood: degradation and decrease in their proportional amounts have been reported by several authors $[6,14$, $20,31,33,43]$. In accordance with this, most of the references report an increase in proportional lignin content $[14,28,33,48]$. However, degradation of the lignin, caused by oxidation processes $[5,14,15]$, was also observed [16, 43]. Cellulose is the most resistant constituent of wood, found to be almost intact even in samples aged up to 4,000 years $[6,13,14]$. Only some changes in the amorphous part occur [19, 43, 48]. The ultrastructure fails mostly in areas with high hemicellulose and lignin content, like the middle lamella [6], but cracks and fractures in the cell wall were also observed [2, 6, 10, 27].

The minor changes in the chemical properties of wood do not seem to have considerable effect on its physical-mechanical behaviour. Some authors report a slight decrease in equilibrium moisture content (MC) [20, 23, 24, 27], while others did not find any differences [7, 13, 39]. Kohara and Okamoto [23] ascertained a lower percentage of shrinkage in the tangential direction and their observation was also confirmed by Obataya [31]. In contrast, Schulz [41] reports an increased degree of shrinkage.

Kohara and Okamoto [23] published an extensive study regarding the mechanical properties of aged wood carried out with samples of varying ages up to 1,300 years. In the case of Hinoki (Chamaecyparis obtusa) softwood, they stated an increase in the mechanical properties like bending and compression strength, Young's modulus and hardness during the first 100 years of aging and a decrease afterwards. Samples of Keyaki (Zelkova serrata) hardwood show a decrease from the beginning of the aging period. Impact bending and shear strength decrease continuously within both species.

Based on tests with samples of various ages and species, some other references report an increase in compression strength $[1,27,31,41]$, Young's modulus [18, 21, 30, 31], hardness [1, 31] and bending and tensile strength [41]. However, publications about declining properties can also be found, regarding bending strength and Young's modulus [1, 28] and shear strength $[1,31]$. In several cases, a more brittle behaviour and lower rupture energy of aged wood were observed [1, 21, 23, 31, 41, 46, 47]. In addition, some authors stated that no considerable changes of the physical-mechanical properties of wood occurred [26, 34, 35, 44, 45].

In the present study, elastic parameters (dynamic elastic moduli and shear moduli) for aged and recent Norway spruce (Picea abies L. Karst.) wood were determined by means of ultrasonic devices. These parameters are of high importance in the design of structural elements and the dynamic elastic modulus in the longitudinal direction is often used for strength estimation and grading of timber.

Ultrasonic techniques are commonly applied to determine elastic parameters in laboratory experiments and for condition assessment of existing wooden structures. Furthermore, they are applied in some industrial grading systems as well [38]. Therefore, the obtained results not only contribute to the existing knowledge about aged wood, but provide useful information about the possibilities of re-using aged wood as well.

\section{Materials and methods}

Since aged wood of high quality is rather expensive and hardly available in appropriate dimensions, a desirable sample size for appropriate statistical significance could not be achieved for conventional mechanical tests. Thus, it was decided to apply nondestructive ultrasonic testing approaches. With this method an opportunity is provided to carry out measurements on boards that still could be used for their original purpose after being non-destructively tested.

\section{Material}

The aged wood tested was provided by Chaletbau Matti AG (Gstaad, Switzerland). This company reuses old wood to build traditional Swiss timber houses. 
The material is washed and is surface treated with ammonia and hydrogen peroxide in order to lighten the colour. Afterwards it is dried at about $70{ }^{\circ} \mathrm{C}$ to kill insects that may be present. Subsequently, the timber is conditioned at $65 \%$ relative humidity $(\mathrm{RH})$ and $20{ }^{\circ} \mathrm{C}$.

Chaletbau Matti purchases its aged wood from companies that deal with wood from deconstructed buildings. Thus, the origin and history of the material usually cannot be determined with high resolution. However, as all boards show signs of weathering (Fig. 1), they obviously have been applied outdoors, most probably under non-load carrying circumstances such as wall covering. Besides degradation of the surface, cracks and biotic infestation by insects and fungi was observed (Fig. 2). Some boards also comprise bores or tree nails. Large knots indicate that the material was not graded before usage.

Timber boards and planks of Norway spruce (P. abies L. Karst.) with dimensions (thickness $\times$ width $\times$ length) 25 to $85 \mathrm{~mm} \times 95$ to $497 \mathrm{~mm} \times 1,230-2,645 \mathrm{~mm}$ were investigated. Their age was determined at TU Dresden (Germany) using dendrochronological methodologies. The regional origin of the boards was supposedly Switzerland and Southern Germany, as dendrochronological investigations show the highest congruence for these areas. The results also provide an estimated age of between 115 and 290 years.

Boards of recent wood with dimensions of (thickness $\times$ width $\times$ length) $45 \times 90 \times 4,000 \mathrm{~mm}$ served as reference samples. The reference sample is chosen based on its corresponding properties to the aged sample (mean, standard deviation) for the density and

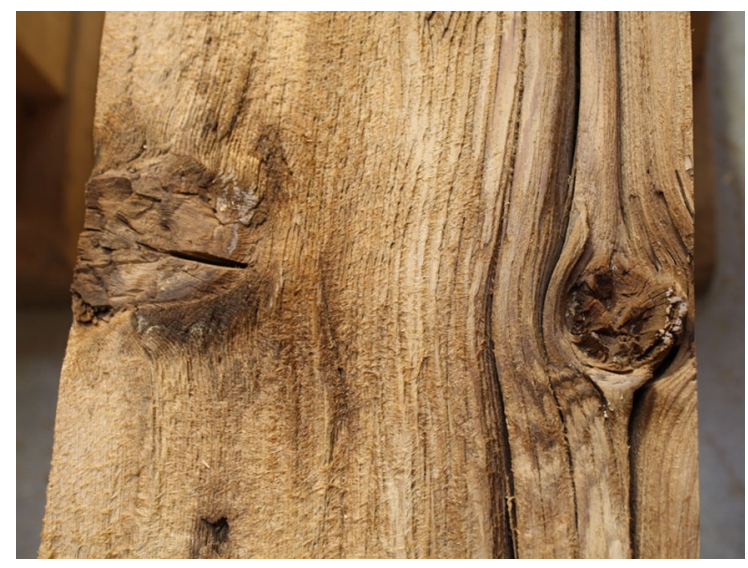

Fig. 1 Weathered surface of an aged board the average annual ring width (arw) in order to make the results of the ultrasound measurements comparable between the two samples: the aged wood and the recent wood. The recent wood specimens were part of a large European grading project investigation, which subjected about 5,000 timber boards to total destructive tests $\left(\right.$ GRADEWOOD $\left.{ }^{1}\right)$. The Swiss contribution comprises of randomly taken Norway Spruce specimens from three different saw mills representing the most relevant forest growth regions of Switzerland: Midlands, Jura and the Alps.

\subsection{Determination of elastic properties by measuring ultrasound velocity}

It is commonly accepted that the sound velocity of a material highly correlates with its elastic parameters, since sound waves generate mechanical oscillations. Methods based on ultrasound velocity are widely accepted and applied to investigate the elastic behaviour of engineering materials, including wood.

Wood is considered to have orthotropic material symmetry [3, 40]. Accordingly, its stiffness matrix contains nine independent elastic coefficients. While the calculation of a shear modulus is based on one particular component, all of the components have to be determined in order to calculate the Young's moduli and Poisson's ratios.

When applying ultrasonic techniques for this purpose, velocities have to be measured in the orthotropic axes and at various angles with these axes as well (explained in detail in Bucur and Archer [9]). This method is quite complex and the necessary specimen preparation and measuring requires much effort. In practice, often only the velocities in the main orthotropic directions are measured, from which the diagonal stiffness values $C_{i i}$ are calculated (Eq. 1):

$\mathrm{C}_{i i}=\mathrm{V}_{i i}^{2} \cdot \rho$

$\mathrm{C}_{i i}$ is the stiffness, $\mathrm{V}_{i i}$ sound velocity of longitudinal waves (polarization direction $i$ parallel to propagation direction $i$ ), $\rho$ is the timber density at $20{ }^{\circ} \mathrm{C}$ and $65 \%$ $\mathrm{RH}$.

A common simplification used in the field of wood science is to approximate the elastic moduli to the stiffness values calculated with Eq. 1:

${ }^{1} \mathrm{http} / / / \mathrm{www}$.woodwisdom.net/mm_files/do_849/GRADE WOOD_ProjectOverview.pdf 


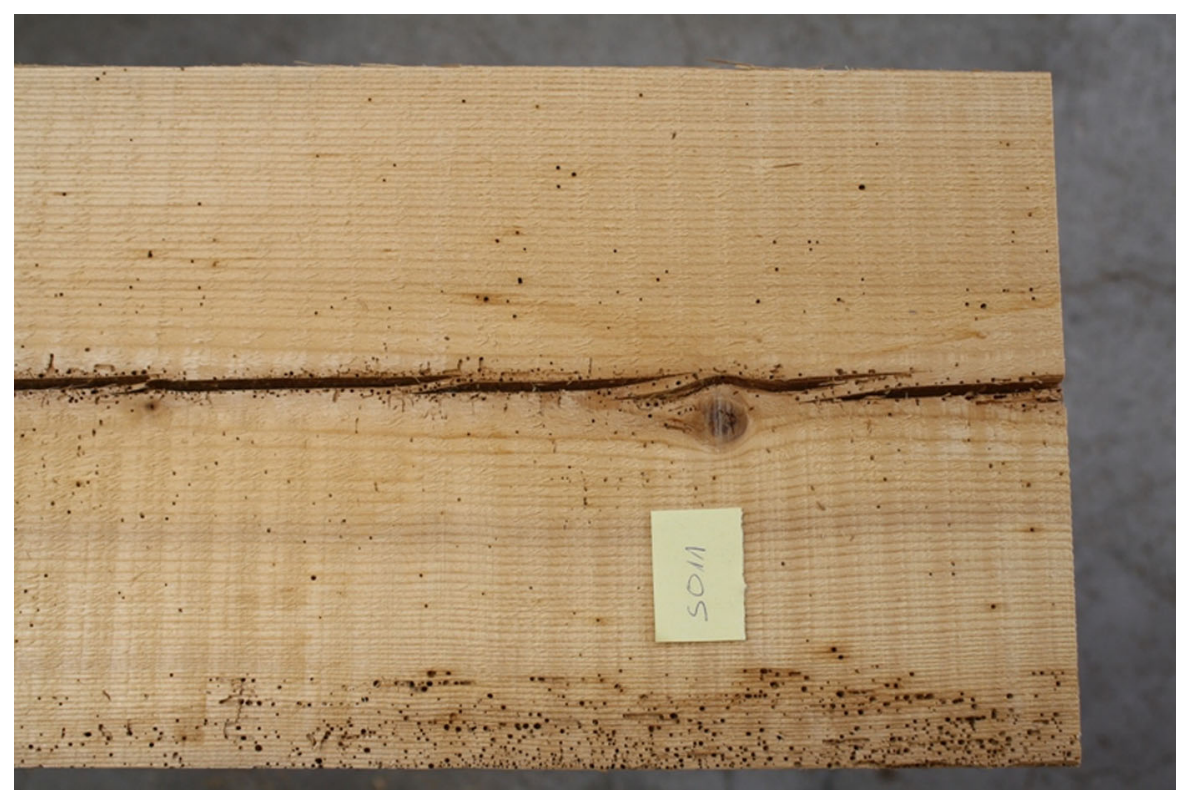

Fig. 2 Damage due to insect attack

$\mathrm{E}_{i i} \approx \mathrm{C}_{i i}$

This can be regarded only as a rough approximation, since the influence of Poisson's ratios is neglected. In particular, for isotropic materials:

$C=E(1-v) /[(1+v)(1-2 v)]$

For orthotropic materials, exact expressions of $\mathrm{E}_{i i}$ in function of $\mathrm{C}_{i i}$ and the Poisson's ratios $v_{i i}$ can be found in Bucur [8]. Based on the dataset of Hearmon [17] for spruce, the approximation leads to errors of approx. 3, 15 and $16 \%$ in longitudinal, radial and tangential direction, respectively.

Due to the limited amount of the available material, the simplified method was applied in the present study. Calculation of the elastic parameters was based on Eq. 1 and the determination of the Poisson's ratios was omitted. To distinguish the determined elastic constants from the Young's modulus, these values are referred to as dynamic elastic moduli.

Shear moduli can be computed exactly according to Eq. 4:

$\mathrm{G}_{i j}=\mathrm{V}_{i j}^{2} \cdot \rho$

$\mathrm{G}_{i j}$ is the shear modulus, $\mathrm{V}_{i j}$ is the sound velocity of shear waves (polarization direction $j$ perpendicular to propagation direction $i$ ), $\rho$ is the timber density at $20{ }^{\circ} \mathrm{C}$ and $65 \% \mathrm{RH}$.
Values presented in this study are averaged values of two perpendicular directions ("ij" and "ji").

\subsection{Testing of the boards}

The testing of the boards provided the ultrasound velocity in fibre direction, from which the dynamic elastic modulus was calculated according to Eq. 1 .

The handheld device named the Sylvatest Duo (Concept Bois Technology) [37] was used to measure the travel time of the transmitted longitudinal waves at a frequency of $22 \mathrm{kHz}$. The two transducers were located perpendicular to two opposite faces, thus implementing the direct measurement method, and were placed in pre-drilled bores to ensure good contact for optimal sound transmission. Travel times were recorded with an accuracy of $1 \mu$ s as an average of four measurements. After entering the length and MC of the specimen, the device provides a referential ultrasound speed for $\mathrm{MC}=12 \%$, which was then used for further calculations.

For each aged board, 2-4 measurement points were chosen depending on the width, preferably on sound areas free from cracks and attacks of fungi or insects. The average of the different values was used for data analysis of the experiments. The recent boards were measured at the centre point only. 
The MC of the boards was measured with an FMW Moisture Detector (Brookhuis Micro-Electronic BV, Enschede, The Netherlands), based on a capacitive method.

The entire testing sample consisted of 112 aged wood and 150 recent wood specimens. From all boards, slices of 5-7 $\mathrm{cm}$ width were cut to provide material for further investigations. In addition, the cross sections were scanned for determination of the age and the average arw (Fig. 3).

\subsection{Testing of small clear specimens}

Testing on small clear specimens was carried out only on material from boards that were suitable for reliable age determination with dendrochronology. 17 of the 112 total aged samples were chosen for determination of dynamic elastic moduli and shear moduli in all anatomical directions that met the criteria of having at least 50 annual rings. Of the reference material, specimens were taken of 34 of the total 150 boards with density and annual ring structure comparable to the corresponding properties of the aged wood specimens. All small specimens had the dimensions (longitudinal $\times$ radial $\times$ tangential) $10 \times 10 \times 10 \mathrm{~mm}$. This specimen size allows the curvature of the annual rings to be neglected, which is a crucial requirement for the investigation of orthotropic behaviour.

The measurements were carried out with an Epoch XT (Panametrics) ultrasonic flaw detector (Fig. 4) that complies with EN12668-1 [12] and is based on the transmitting pulse method. For determining the dynamic elastic moduli, longitudinal waves with a frequency of $2.25 \mathrm{MHz}$ were generated with an Olympus A133S transducer (diameter $12.7 \mathrm{~mm}$ ). Shear moduli were calculated based on velocity of shear waves generated by a Staveley S-0104 transducer (diameter $12.7 \mathrm{~mm}$ ) at a frequency of $1 \mathrm{MHz}$. In both cases, a pair of selected transducers was used: one of them being the emitter and the other one the receiver. Specimens were fixed using a clamping apparatus that ensured constant contact pressure and the coupling gel Ultrasonic Couplant II (Control Tech) was used to ensure good coupling.

The received signal was recorded at a sampling frequency of $100 \mathrm{MHz}$. The peak of the first received signal was amplified to $100 \%$ of the display scale and the delay of the signal was measured at the flank of the corresponding (longitudinal or transversal) incoming wave at $30 \%$ of the display scale. The travel time was recorded with an accuracy of $0.01 \mu$ s. The delay time of the transducers was assessed by calibration with aluminium disks and subtracted from the measured values. After the correction of the travel time, the dynamic elastic moduli and shear moduli were calculated according to Eqs. 1 and 4, respectively.

The measurements were carried out in normal climate $\left(20{ }^{\circ} \mathrm{C}\right.$ and $\left.65 \% \mathrm{RH}\right)$ after the specimens reached equilibrium $\mathrm{MC}$.

\section{Results}

\subsection{Dynamic elastic modulus of the boards}

Figure 3 shows the dynamic elastic modulus values for aged wood and recent wood specimens. Regression analysis shows that the coefficients of correlation and the slopes of the regression lines (Fig. 5) are quite similar for both groups of specimens and are compliant with well-known data for this type of

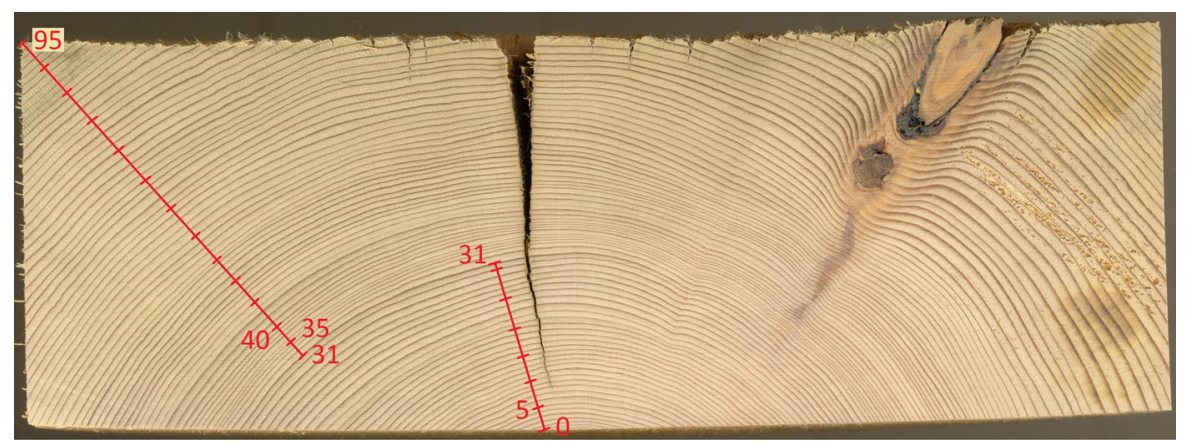

Fig. 3 Determination of the average annual ring width 


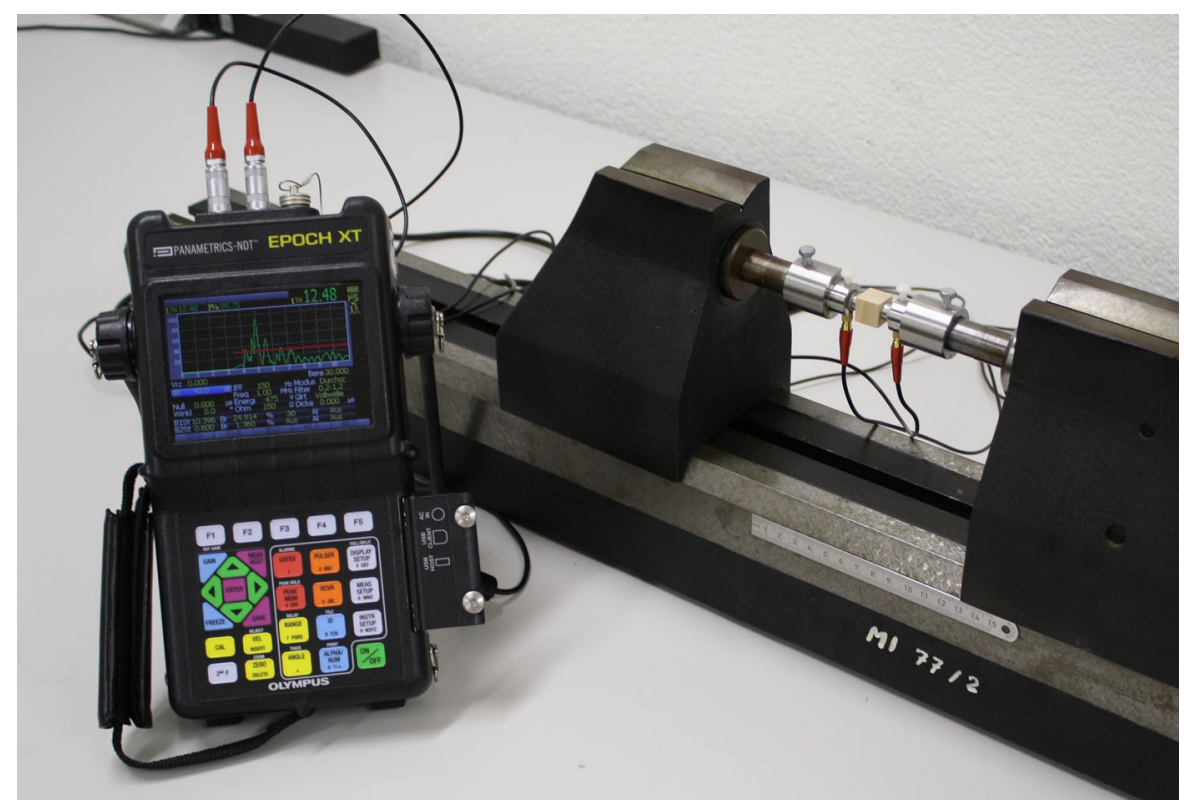

Fig. 4 Testing with Epoch XT

measurement [42]. The dynamic elastic modulus of aged wood is shifted to higher values than that of recent wood. However, predictability of the structural performance of the tested specimens based on ultrasonic measurements would be of the same quality as long as the variance of the observations along the regression line can be considered similar for both subsamples. Figure 5 confirms that this is the case.

To assess the suitability of the data for further evaluation, the distributions of dynamic elastic modulus, density and average arw were investigated. By means of probability plots, the three investigated timber material properties were found to be best represented with normal distributions. Based on the measurements of the laboratory, the distribution parameters were assessed by means of Maximum Likelihood estimations and the corresponding probability density functions (pdfs) were assessed as given in Figs. 6, 7, and 8.

For the dynamic elastic modulus (Fig. 6) the mean values and standard deviations were almost identical for aged and recent timber specimens and the pdfs are rather congruent. In contrast, the pdfs of the timber densities (Fig. 7) differ clearly between specimens of aged and recent wood (mean values of densities: 450 vs. $420 \mathrm{~kg} / \mathrm{m}^{3}$ ). The mean values of the annual ring widths are again close to each other,

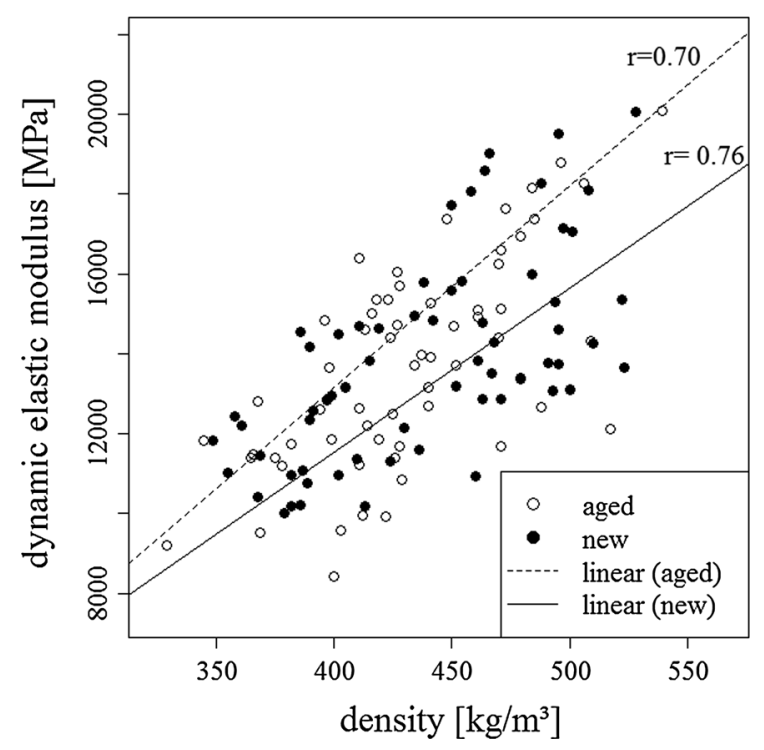

Fig. 5 Scatter plot of dynamic elastic modulus over density for the boards

but the standard deviation is much higher for recent wood specimens (Fig. 8). Due to the high standard deviation of the annual ring width, the pdf of the normal distribution runs into negative values. Hence the pdf for average arw is assumed to be truncated normal distributed. 


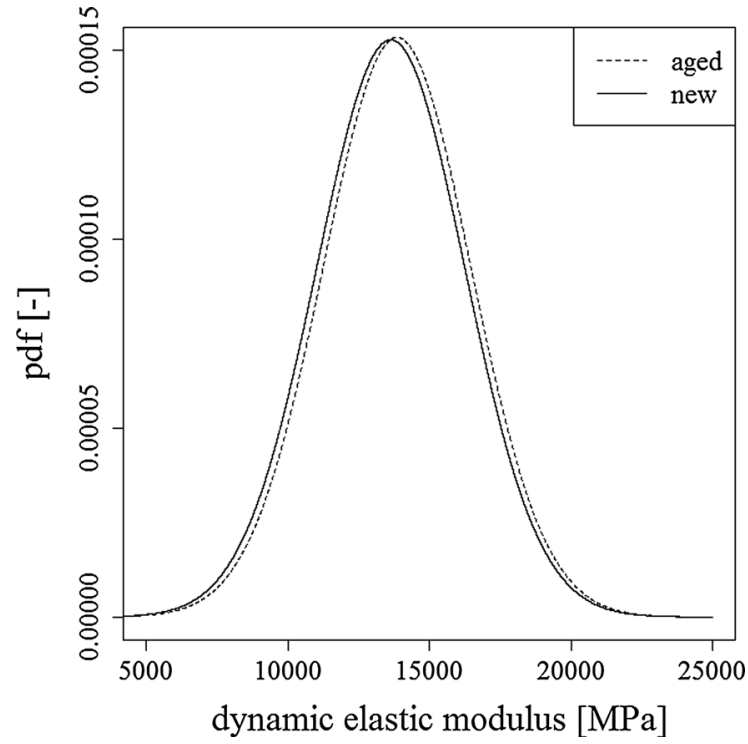

Fig. 6 Probability density functions of dynamic elastic modulus for the boards

Table 1 Results of the multiple linear analysis

\begin{tabular}{lrrrl}
\hline & $E\left(\beta_{n}\right)$ & $\operatorname{Var}\left(\beta_{n}\right)$ & $t$ value & $p$ value \\
\hline Intercept & $-4,210.8$ & $1,731.1$ & -2.432 & $0.01572^{*}$ \\
Age (recent) & $3,116.5$ & $2,115.4$ & 1.473 & 0.14199 \\
Density & 45.8 & 4.0 & 11.511 & $<2 \mathrm{e}-16^{*}$ \\
Ring width & -409.5 & 108.3 & -3.782 & $0.00020^{*}$ \\
Age & -10.9 & 4.9 & -2.227 & $0.02684^{*}$ \\
$\quad$ (recent):density & & & & \\
\hline
\end{tabular}

Residual standard error: 1,641 on 242 degrees of freedom. Multiple $R^{2}: 0.6131$

$E\left(\beta_{n}\right)$ estimated value of the regression coefficients, $\operatorname{Var}\left(\beta_{n}\right)$ standard error (variance) of the regression coefficients, $t$ value, $p$ value parameters of the significance test (two-sided $t$-test)

* Significant at a confidence level of $95 \%$

To investigate the effects of the influencing factors age, density and arw on the dynamic elastic modulus, a multiple linear regression was carried out. Interactions were only allowed between the factors age and density. Based on residual analysis, three outliers were removed from the data set. The parameters of the regression analysis are given in Table 1. Based on these, a significant main effect of density and average arw on the dynamic elastic modulus can be stated. In addition, an interaction between age and density was observed, so the effect of density may not be the same for the aged as for the recent sample. However, no significant main effect of the age was shown.

\subsection{Elastic parameters of the small clear specimens}

Table 2 shows the values of dynamic elastic moduli and shear moduli of aged wood determined on clear specimens. In Table 4 a comparison between the results for aged and recent wood is shown, together with reference values measured with similar methods [22, 25, 29].

It is well known that elastic parameters tend to be higher when determined by ultrasonic methods than those obtained in mechanical tests [8]. Ozyhar et al. [32] found that calculations based on the simplified equation (Eq. 1) lead to an overestimation of the elastic moduli. According to Dívós and Tanaka [11] and Keunecke et al. [22], the difference can range from 10 to $40 \%$. However, in the case of values determined with the Epoch XT device in this study, the difference exceeds this rate in some cases, especially in the case of dynamic elastic modulus values in the longitudinal direction. In addition to the overestimation due to the calculation method, the high frequencies applied during testing may also contribute an effect on the latter [8].

Because of the high measuring frequency, the inhomogeneity of wood must also be considered. As a consequence of desiring a low wavelength/sample dimensions ratio [9], the applied frequency has to be remarkably higher for small specimens, than it is usual by measuring timber. This makes the measurement more sensitive to local defects and inhomogeneities. However, given that the specimens are small, a careful specimen selection remarkably decreases the probability of defects in the investigated material. Furthermore, as the specimens were obtained from different locations of the cross section, the inhomogeneity within a given sample should be compensated. As results for the small specimens are in good agreement with those of the boards, we suppose that property variations along the stem did not have a significant effect on the results either.

Although the measurements were performed in a constant climate, small variations in the $\mathrm{MC}$ of the specimens can occur that can influence the ultrasonic velocity and thus the results. Therefore, their possible effect has been assessed.

Based on sorption data of the investigated materials (experiment not reported here), the variation of the MC is under $0.4 \%$ within one specimen group, while the 
Table 2 Dynamic elastic moduli and shear moduli of the aged specimens

\begin{tabular}{|c|c|c|c|c|c|c|c|c|c|c|}
\hline No. & $\begin{array}{l}\text { Age } \\
\text { (years) }\end{array}$ & $n^{\mathrm{a}}$ & $\begin{array}{l}\rho \\
\left(\mathrm{kg} / \mathrm{m}^{3}\right)\end{array}$ & $\begin{array}{l}\text { arw } \\
(\mathrm{mm})\end{array}$ & $\begin{array}{l}E_{\mathrm{L}} \\
(\mathrm{MPa})\end{array}$ & $\begin{array}{l}E_{\mathrm{R}} \\
(\mathrm{MPa})\end{array}$ & $\begin{array}{l}\mathrm{E}_{T} \\
(\mathrm{MPa})\end{array}$ & $\begin{array}{l}G_{\mathrm{LR}} \\
(\mathrm{MPa})\end{array}$ & $\begin{array}{l}G_{\mathrm{LT}} \\
(\mathrm{MPa})\end{array}$ & $\begin{array}{l}G_{\mathrm{RT}} \\
(\mathrm{MPa})\end{array}$ \\
\hline \multicolumn{11}{|l|}{ S016 } \\
\hline Mean & 116 & 6 & 388 & 2.2 & 27,380 & 2,227 & 713 & 679 & 718 & 98 \\
\hline $\operatorname{cov}(\%)$ & & & 7.5 & 19.0 & 14.8 & 9.7 & 10.3 & 13.7 & 16.6 & 20.3 \\
\hline \multicolumn{11}{|l|}{ S099 } \\
\hline Mean & 128 & 7 & 379 & 2.9 & 26,484 & 2,149 & 748 & 785 & 677 & 89 \\
\hline $\operatorname{cov}(\%)$ & & & 2.5 & 3.8 & 4.9 & 2.8 & 9.9 & 24.1 & 14.0 & 22.7 \\
\hline \multicolumn{11}{|l|}{ S072 } \\
\hline Mean & 133 & 6 & 427 & 1.9 & 29,601 & 2,396 & 654 & 884 & 691 & 116 \\
\hline $\operatorname{cov}(\%)$ & & & 2.2 & 15.1 & 1.6 & 4.1 & 30.4 & 19.5 & 21.2 & 26.4 \\
\hline \multicolumn{11}{|l|}{ S012 } \\
\hline Mean & 144 & 7 & 375 & 3.0 & 19,616 & 2,564 & 818 & 1,015 & 912 & 99 \\
\hline $\operatorname{cov}(\%)$ & & & 2.7 & 16.2 & 5.6 & 3.9 & 15.3 & 6.6 & 10.1 & 25.6 \\
\hline \multicolumn{11}{|l|}{ S078 } \\
\hline Mean & 161 & 7 & 386 & 1.7 & 17,520 & 2,621 & 847 & 992 & 840 & 101 \\
\hline $\operatorname{cov}(\%)$ & & & 3.0 & 9.5 & 7.6 & 2.3 & 6.5 & 13.4 & 13.6 & 14.9 \\
\hline \multicolumn{11}{|l|}{ S092 } \\
\hline Mean & 163 & 6 & 433 & 1.6 & 24,524 & 2,959 & 654 & 1,182 & 972 & 117 \\
\hline $\operatorname{cov}(\%)$ & & & 1.7 & 6.7 & 10.0 & 1.0 & 15.4 & 10.2 & 5.9 & 33.6 \\
\hline \multicolumn{11}{|l|}{ S079 } \\
\hline Mean & 164 & 6 & 553 & 1.7 & 37,853 & 3,400 & 950 & 1,145 & 1,060 & 148 \\
\hline $\operatorname{cov}(\%)$ & & & 2.3 & 10.2 & 6.5 & 3.1 & 25.0 & 24.7 & 19.1 & 20.0 \\
\hline \multicolumn{11}{|l|}{ S061 } \\
\hline Mean & 166 & 6 & 469 & 2.2 & 27,035 & 2,931 & 1,046 & 998 & 1,144 & 127 \\
\hline $\operatorname{cov}(\%)$ & & & 7.6 & 12.0 & 20.1 & 11.8 & 65.6 & 25.6 & 30.4 & 16.0 \\
\hline \multicolumn{11}{|l|}{ S098 } \\
\hline Mean & 171 & 8 & 385 & 1.3 & 20,359 & 2,807 & 568 & 928 & 922 & 96 \\
\hline $\operatorname{cov}(\%)$ & & & 1.3 & 11.8 & 6.5 & 3.7 & 21.7 & 25.1 & 12.9 & 24.8 \\
\hline \multicolumn{11}{|l|}{ S088 } \\
\hline Mean & 182 & 7 & 436 & 1.2 & 27,391 & 2,685 & 922 & 815 & 790 & 112 \\
\hline $\operatorname{cov}(\%)$ & & & 2.6 & 6.6 & 4.1 & 3.2 & 20.9 & 14.2 & 10.8 & 28.1 \\
\hline \multicolumn{11}{|l|}{ S003 } \\
\hline Mean & 184 & 7 & 411 & 2.4 & 25,492 & 2,341 & 601 & 946 & 693 & 109 \\
\hline $\operatorname{cov}(\%)$ & & & 6.7 & 32.4 & 27.3 & 9.4 & 39.8 & 40.2 & 42.0 & 21.4 \\
\hline \multicolumn{11}{|l|}{ S076 } \\
\hline Mean & 199 & 7 & 361 & 2.3 & 20,967 & 2,296 & 610 & 827 & 680 & 94 \\
\hline $\operatorname{cov}(\%)$ & & & 5.7 & 18.2 & 16.6 & 8.3 & 16.3 & 23.0 & 14.9 & 12.1 \\
\hline \multicolumn{11}{|l|}{ S086 } \\
\hline Mean & 286 & 7 & 402 & 0.7 & 23,934 & 2,373 & 775 & 904 & 655 & 99 \\
\hline $\operatorname{cov}(\%)$ & & & 3.2 & 27.9 & 4.3 & 7.1 & 11.5 & 19.0 & 10.8 & 25.6 \\
\hline \multicolumn{11}{|l|}{ S007 } \\
\hline Mean & n.a. ${ }^{\mathrm{b}}$ & 6 & 415 & 1.0 & 23,783 & 2,607 & 945 & 797 & 792 & 117 \\
\hline $\operatorname{cov}(\%)$ & & & 2.4 & 16.7 & 5.3 & 1.1 & 5.4 & 11.1 & 5.3 & 18.4 \\
\hline
\end{tabular}


Table 2 continued

\begin{tabular}{|c|c|c|c|c|c|c|c|c|c|c|}
\hline No. & $\begin{array}{l}\text { Age } \\
\text { (years) }\end{array}$ & $n^{\mathrm{a}}$ & $\begin{array}{l}\rho \\
\left(\mathrm{kg} / \mathrm{m}^{3}\right)\end{array}$ & $\begin{array}{l}\text { arw } \\
(\mathrm{mm})\end{array}$ & $\begin{array}{l}E_{\mathrm{L}} \\
(\mathrm{MPa})\end{array}$ & $\begin{array}{l}E_{\mathrm{R}} \\
(\mathrm{MPa})\end{array}$ & $\begin{array}{l}\mathrm{E}_{T} \\
(\mathrm{MPa})\end{array}$ & $\begin{array}{l}G_{\mathrm{LR}} \\
(\mathrm{MPa})\end{array}$ & $\begin{array}{l}G_{\mathrm{LT}} \\
(\mathrm{MPa})\end{array}$ & $\begin{array}{l}G_{\mathrm{RT}} \\
(\mathrm{MPa})\end{array}$ \\
\hline \multicolumn{11}{|l|}{ S013 } \\
\hline Mean & n.a. ${ }^{\text {b }}$ & 7 & 416 & 1.8 & 18,227 & 2,610 & 1,093 & 1,045 & 1,186 & 118 \\
\hline $\operatorname{cov}(\%)$ & & & 5.8 & 22.4 & 18.7 & 10.3 & 29.5 & 19.3 & 19.3 & 20.5 \\
\hline \multicolumn{11}{|l|}{ S033 } \\
\hline Mean & n.a. ${ }^{\text {b }}$ & 7 & 371 & 1.1 & 13,933 & 2,207 & 666 & 923 & 958 & 101 \\
\hline $\operatorname{cov}(\%)$ & & & 2.8 & 13.3 & 5.2 & 3.4 & 2.6 & 7.3 & 13.3 & 16.0 \\
\hline \multicolumn{11}{|l|}{ S082 } \\
\hline Mean & n.a. ${ }^{b}$ & 7 & 407 & 1.4 & 25,429 & 2,697 & 746 & 837 & 689 & 112 \\
\hline $\operatorname{cov}(\%)$ & & & 3.1 & 59.6 & 12.0 & 6.2 & 17.1 & 11.3 & 16.1 & 22.2 \\
\hline
\end{tabular}

${ }^{a} n$ varies because all specimens that could be prepared from the material available were tested

b Age determination failed because the pattern of annual ring width could not be matched with existing chronologies

Table 3 Coefficients of correlation between age and stiffness values normalized by density

\begin{tabular}{lllllll}
\hline$r$ & $\mathrm{E}_{L} / \rho$ & $\mathrm{E}_{R} / \rho$ & $\mathrm{E}_{T} / \rho$ & $G_{\mathrm{LR}} / \rho$ & $G_{\mathrm{LT}} / \rho$ & $G_{\mathrm{RT}} / \rho$ \\
\hline Age & 0.269 & 0.027 & 0.007 & 0.146 & 0.239 & 0.162 \\
\hline
\end{tabular}

difference between the average values of aged and recent specimens is around $0.5 \%$. Ozyhar et al. [32] found that the effect of moisture variation is largest for shear waves in the LR direction. They reported a decrease of $21 \%$ in the corresponding sound velocity by a moisture difference of $9.1 \%$ under the fibre saturation point. According to these findings, a moisture variation of $0.5 \%$ may cause approximately $1.2 \%$ variation in the sound velocity and thus, $2.4 \%$ in the elastic parameters. This uncertainty is of the same order to the one introduced by the measurement equipment and is considered negligible in the investigations.

Table 4 Comparison of dynamic elastic moduli and shear moduli of aged and new specimens of Norway spruce

\begin{tabular}{|c|c|c|c|c|c|c|c|c|c|c|}
\hline & & $n$ & $\rho\left(\mathrm{kg} / \mathrm{m}^{3}\right)$ & $\operatorname{arw}(\mathrm{mm})$ & $\mathrm{E}_{L}(\mathrm{MPa})$ & $\mathrm{E}_{R}(\mathrm{MPa})$ & $\mathrm{E}_{T}(\mathrm{MPa})$ & $G_{\mathrm{LR}}(\mathrm{MPa})$ & $G_{\mathrm{LT}}(\mathrm{MPa})$ & $G_{\mathrm{RT}}(\mathrm{MPa})$ \\
\hline Aged & Mean & 114 & 413 & 1.8 & 24,090 & 2,581 & 786 & 924 & 846 & 109 \\
\hline All & $\operatorname{cov}(\%)$ & & 3.7 & 17.7 & 10.1 & 5.4 & 20.2 & 18.1 & 16.2 & 21.7 \\
\hline New & Mean & 128 & 515 & 1.8 & 19,516 & 2,153 & 1,739 & 876 & 867 & 120 \\
\hline Origin 1 & $\operatorname{cov}(\%)$ & & $7.4 \%$ & 21.1 & 13.0 & 7.2 & 25.1 & 12.0 & 11.0 & 9.3 \\
\hline New & Mean & 52 & 435 & 3.1 & 14,556 & 2,016 & 1,081 & 883 & 826 & 104 \\
\hline Origin 2 & $\operatorname{cov}(\%)$ & & 11.9 & 25.9 & 11.8 & 12.3 & 40.5 & 15.8 & 25.2 & 11.1 \\
\hline New & Mean & 180 & 444 & 1.9 & 14,434 & 2,074 & 927 & 972 & 674 & 100 \\
\hline Origin 3 & $\operatorname{cov}(\%)$ & & 6.0 & 23.4 & 10.9 & 12.1 & 18.0 & 18.0 & 20.1 & 14.3 \\
\hline New & Mean & 340 & 465 & 2.1 & 16,100 & 2,089 & 1,217 & 926 & 863 & 107 \\
\hline All & $\operatorname{cov}(\%)$ & & 10.8 & 33.2 & 19.1 & 11.0 & 40.5 & 16.9 & 18.8 & 14.6 \\
\hline \multirow[t]{2}{*}{ Ref. $^{a}$} & Mean & 120 & 400 & n.a. & 13,800 & 1,800 & 1,170 & 617 & 587 & 53 \\
\hline & $\operatorname{cov}(\%)$ & & 9.7 & n.a. & 20.0 & 10.6 & 21.1 & 12.1 & 10.2 & 10.9 \\
\hline \multirow[t]{2}{*}{ Ref. } & Mean & 10 & 454 & n.a & 19,207 & 2,103 & 637 & 868 & 710 & 114 \\
\hline & $\operatorname{cov}(\%)$ & & n.a. & n.a. & 2.3 & 9.1 & 9.1 & 13.1 & 8.5 & 7.8 \\
\hline \multirow[t]{2}{*}{ Ref. $^{\mathrm{c}}$} & Mean & 20 & 435 & n.a. & 16,373 & 2,075 & 963 & 870 & 708 & 78 \\
\hline & $\operatorname{cov}(\%)$ & & n.a. & n.a. & 11.2 & 9.6 & 47.5 & 14.8 & 15.1 & 15.7 \\
\hline
\end{tabular}

\footnotetext{
a $[22]$

b $[25]$

c $[29]$
} 


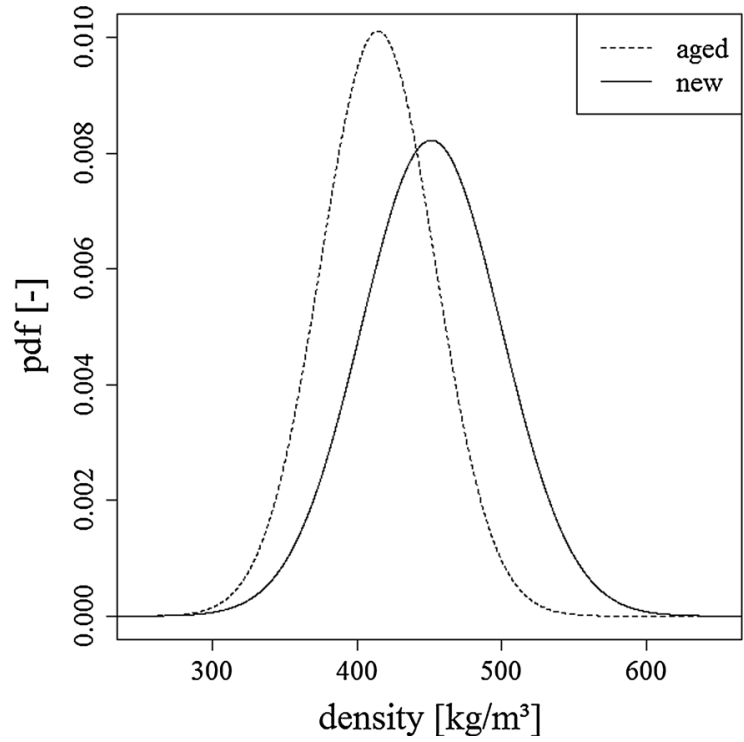

Fig. 7 Probability density functions of density for the boards

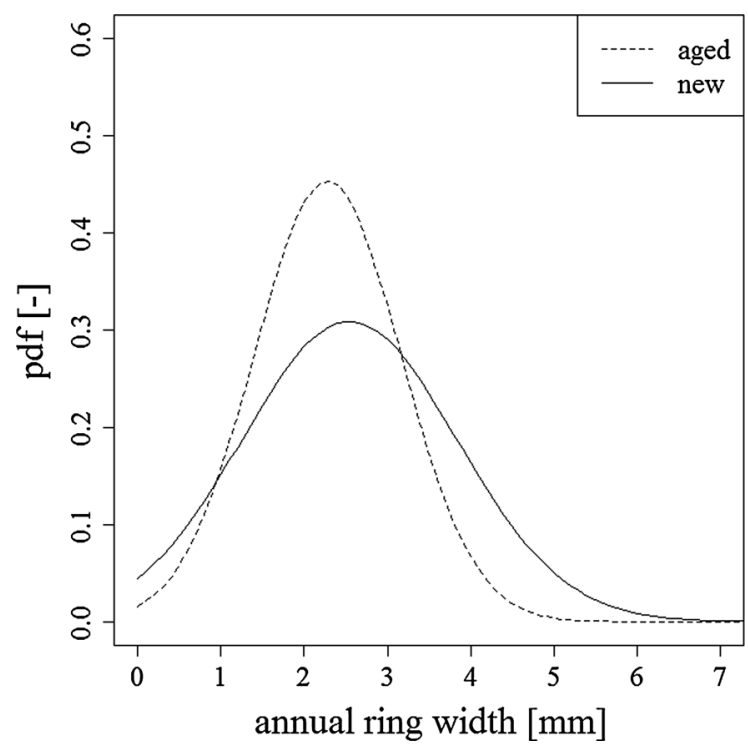

Fig. 8 Probability density functions of the average annual ring width for the boards

According to the previous statements, a comparison between aged and recent wood is possible.

The mean values and coefficients of variations (cov) of dynamic elastic moduli and shear moduli of the aged specimens are given in Table 2, ordered by increasing age. To see a possible effect of aging on these properties, coefficients of correlation were calculated between age and the stiffness values

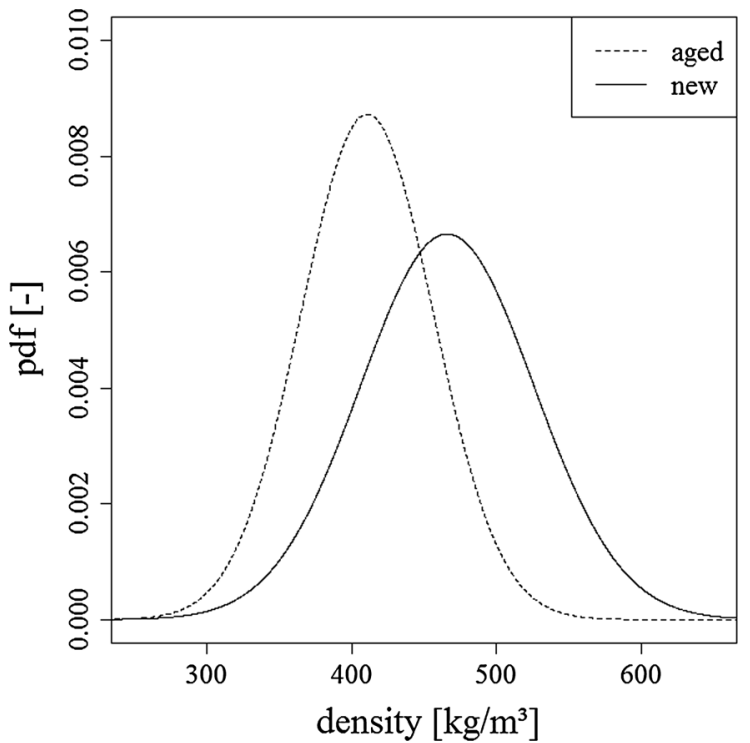

Fig. 9 Probability density functions of density for the clear specimens

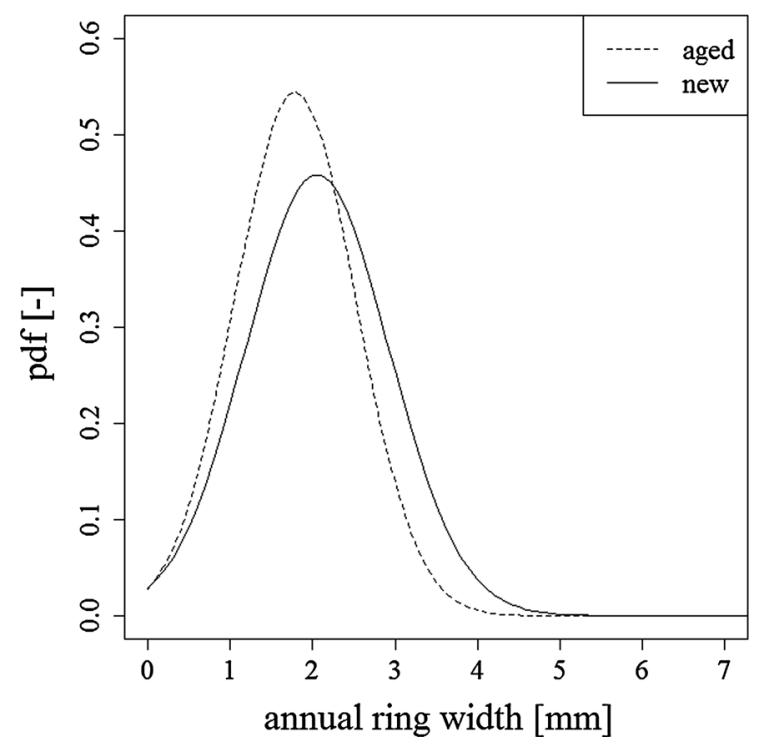

Fig. 10 Probability density functions of the average annual ring width for the clear specimens

normalized by density (Table 3 ). Based on these, no correlation between age and stiffness can be stated.

However, the dynamic elastic modulus in the longitudinal direction is clearly higher in aged wood than in recent wood, as can be seen in Table 4. The same can be said for the radial direction, but no significant difference can be confirmed for shear 
moduli and the dynamic elastic modulus in the tangential direction, partly because of high variations. With the exception of the dynamic elastic modulus for aged wood in the longitudinal direction, all measured values are in the same range as the references.

While the variation of density within a sample is quite low for all samples, with the highest cov being $10.8 \%$, average arw values show remarkable differences in some cases even within the same board, with values of cov varying between 3.8 and $59.6 \%$. High variations are a consequence of specimens cut from different areas of the cross section.

Figures 9 and 10 show the density functions of raw density and arw of the clear specimens. The pdf of the raw density looks similar to that of the boards, but the average arw is considerably lower for the clear specimens. This is a consequence of the sampling procedure, as it was biased to specimens with at least 50 annual rings and specimens with a higher number of annual rings in a certain cross section will have lower average ring widths.

\section{Discussion and conclusions}

The results of the tested boards show higher values of longitudinal dynamic elastic modulus for the sample of aged wood and a similar difference was found for the clear specimens. For the latter, the dynamic elastic modulus in the radial direction also results in higher values, but no difference can be observed for dynamic elastic modulus in the tangential direction and for shear moduli in general. Based on these outcomes, no significant correlation between age and elastic parameters can be proven. The differences in values of dynamic elastic moduli and shear moduli between aged and recent wood are supposedly caused by the annual ring structure and its influence on the elastic behaviour of wood. A significant effect of the average annual ring width was shown by means of regression analysis for the data of the boards. Minor changes in the cell wall structure due to aging may have an effect on the velocity of ultrasound and could also affect the elastic wood properties [1].

The board measurements reveal a relationship between dynamic elastic modulus and wood density being nearly the same for aged and recent wood specimens. Since both, variation along the regression lines and correlation coefficients, are similar for aged and recent specimens, the estimation of dynamic elastic modulus by means of ultrasonic devices can be applied for aged wood based on the grading methodologies developed for recent wood [36] and are given in today's codes and standards (e. g. EN14081). However, it should be considered that the relationship between values based on ultrasonic measurements and determined by mechanical tests is not necessarily the same for aged wood, as it is for recent wood [1].

Acknowledgments Special thanks go to Prof. Dr. Dr. Habil. Claus-Thomas Bues and Björn Günther (Dresden University of Technology) for dating the aged samples. The authors would also like to thank Chaletbau Matti (Saanen, Switzerland) for providing aged wood for the study and Melanie Wetzig for her contribution in the measurements.

\section{References}

1. Attar-Hassan G (1976) The effect of ageing on the mechanical properties of Eastern white pine. Bull Assoc Preserv Technol 8(3):64-73

2. Blanchette RA, Haight JE, Koestler RJ, Hatchfield PB, Arnold D (1994) Assessment of deterioration in archaeological wood from ancient Egypt. J Am Inst Conserv 33(1):55-70

3. Bodig J, Jayne BA (1993) Mechanics of wood and wood composites. Krieger, Malabar

4. Borgin K (1973) The inherent durability of wood. Paper presented at the B.W.P.A. Annual Convention

5. Borgin K, Faix O, Schweers W (1975) Effect of aging on lignins of wood. Wood Sci Technol 9(3):207-211

6. Borgin K, Parameswaran N, Liese W (1975) Effect of aging on ultrastructure of wood. Wood Sci Technol 9(2):87-98

7. Buck RD (1952) A note on the effect of age on the hygroscopic behavior of wood. Stud Conserv 1(1):39-44

8. Bucur V (2006) Acoustics of Wood (Springer series in wood science). Springer, Berlin

9. Bucur V, Archer RR (1984) Elastic constants for wood by an ultrasonic method. Wood Sci Technol 18(4):255-265

10. Chowdchury KA, Preston RD, White RK (1967) Structural changes in some ancient Indian timbers. Proc R Soc B 168:148-157

11. Dívós F, Tanaka T (2005) Relation between static and dynamic modulus of elasticity of wood. Acta Silv Lignaria Hung 1:105-110

12. EN-12668-1 (2010) Non-destructive testing - characterization and verification of ultrasonic examination equipment-part 1: instruments. European Committee for Standardization, Brussels, Belgium

13. Erhardt D, Mecklenburg MF, Tumosa CS, Olstad TM (1996) New versus old wood: differences and similarities in physical, mechanical, and chemical properties. Paper presented at the International Council of Museums-Committee for Conservation 11th triennial meeting, London

14. Fengel D (1991) Aging and fossilization of wood and its components. Wood Sci Technol 25(3):153-177 
15. Fengel D, Stocklhuber P (1985) Comparison of extracts and lignin from green and seasoned pine wood (Pinus Sylvestris L.). Holz Als Roh-und Werkst 43(11):447-450

16. Ganne-Chédeville C, Jääskeläinen A-S, Froidevaux J, Hughes M, Navi P (2011) Natural and artificial ageing of spruce wood as observed by FTIR-ATR and UVRR spectroscopy. Holzforschung 66:163-170

17. Hearmon RFS (1948) The elasticity of wood and plywood. Great Britain, Forest Products Research, London

18. Holz D (1981) Zum alterungsverhalten des werkstoffes holz-einige ansichten, untersuchungen, ergebnisse. Holztechnologie 22(2):80-85

19. Inagaki T, Mitsui K, Tsuchikawa S (2008a) NIR archaeometry as a powerful tool for investigating the archaeological wood-investigation of thermal degradation mechanism of softwood and hardwood. Paper presented at the wood science for preservation of cultural heritage: mechanical and biological factors, Braga, Portugal, 5-7 Nov, 2008

20. Inagaki T, Yonenobu H, Tsuchikawa S (2008b) Nearinfrared spectroscopic monitoring of the water adsorption/ desorption process in modern and archaeological wood. Appl Spectrosc 62(8):860-865

21. Kawai S, Yokoyama M, Matsuo M, Sugiyama J (2008) Research on the aging of wood in RISH. Paper presented at the wood science for preservation of cultural heritage: mechanical and biological factors, Braga, Portugal, 5-7 Nov, 2008

22. Keunecke D, Sonderegger W, Pereteanu K, Luthi T, Niemz P (2007) Determination of Young's and shear moduli of common yew and Norway spruce by means of ultrasonic waves. Wood Sci Technol 41(4):309-327. doi:10.1007/s00226-006-0107-4

23. Kohara J, Okamoto H (1955) Studies of Japanese old timbers. Sci Rep Saikyo Univ 7(1):9-20

24. Kurtoglu A (1983) The properties of sorption of old spruce timber. Holzforsch Holzverw 35(6):125-126

25. Merz T (2009) Messung der Schallgeschwindigkeit in den drei Hauptschnittrichtungen mit Longitudinal- und Transversalwellen. BSc thesis, ETH Zürich, Zurich, Switzerland

26. Mombächer R (1993) Altholz. Holz-Lexikon. DRW, Stuttgart

27. Narayanamurti D, Ghosh SS, Prasad BN, George J (1958) Note on examination of an old timber specimen. Holz Als Roh-und Werkst 16(7):245-247

28. Narayanamurti D, Prasad BN, Verma GM (1961) Untersuchungen an alten Hölzern 3. Ein altes Pterocarpus Holz aus Tirupathi. Holz Als Roh-und Werkst 19(2):48-50

29. Nisoli L (2009) Klimaabhängigkeit elasto-mechanischer Kenngrössen von Holz in drei Hauptrichtungen. BSc thesis, ETH Zurich, Zurich, Switzerland

30. Noguchi T, Obataya E, Ando K (2011) Effects of ageing on the vibrational properties of Akamatsu (Pinus densiflora) wood. Paper presented at the wood culture and science, Kyoto, 6-9 Aug 2011

31. Obataya E (2007) Characteristics of aged wood and Japanes traditional coating technology for wood protection. Paper presented at the conserver aujourd"hui: les "Vieillissements" du bois, Musee de la musique à la Cité de la musique, Paris, France

32. Ozyhar T, Hering S, Sanabria SJ, Niemz P (2012) Determining moisture-dependent elastic characteristics of beech wood by means of ultrasonic waves. Wood Sci Technol. doi: 10.1007/s00226-012-0499-2
33. Popescu CM, Dobele G, Rossinskaja G, Dizhbite T, Vasile C (2007) Degradation of lime wood painting supports evaluation of changes in the structure of aged lime wood by different physico-chemical methods. J Anal Appl Pyrol 79(1-2):71-77. doi:10.1016/j.jaap.2006.12.014

34. Rug W, Seemann A (1988) Festigkeit von altholz. Holztechnologie 29(4):186-190

35. Saito Y, Shida S, Ohta M, Yamamoto H, Tai T, Ohmura W, Makihara H, Noshiro S, Goto O (2008) Deterioration character of aged timbers insect damage and material aging of rafters in a historic building of Fukushoji-temple. Mokuzai Gakkaishi 54(5):255-262

36. Sandomeer MK, Köhler J, Faber MH (2008) Probabilistic output control of structural timber-modelling approach. Paper presented at the 41 st meeting, international council for research and innovation in building and construction, $\mathrm{St}$. Andrews, Canada

37. Sandoz J-L (1990) Grading and reliability of construction timber, validation of the ultrasound method. EPFL, Lausanne

38. Sandoz JL, Benoit Y (2007) Timber grading machine using ultrasonic and density measurements: Triomatic. Paper presented at the 15th international symposium on nondestructive testing of wood, Duluth, MN, USA, 10-12 Sep 2007

39. Schniewind AP (1990) Physical and mechanical-properties of archaeological wood. In: Rowell R, Barbour RJ (eds) Archaeological wood properties, chemistry, and preservation. Advances in chemistry, vol 225. American Chemical Society, Washington, pp 87-109

40. Schniewind AP, Barrett JD (1972) Wood as a linear orthotropic viscoelastic material. Wood Sci Technol 6(1):43-57

41. Schulz H, von Aufsess H, Verron T (1984) Eigenschaften eines Fichtenbalkens aus altem Dachstuhl. Holz Roh Werkst 42(3): 109

42. Steiger R (1996) Mechanische eigenschaften von Schweizer fichten-bauholz bei biege-, zug-, druck- und kombinierter M/N-beanspruchung. Doctoral thesis, ETH Zurich, Basel, Switzerland

43. Tsuchikawa S, Yonenobu H, Siesler HW (2005) Nearinfrared spectroscopic observation of the ageing process in archaeological wood using a deuterium exchange method. Analyst 130(3):379-384. doi:10.1039/B412759e

44. Unger A, Schniewind AP, Unger W (2001) Conservation of wood artifacts. Springer, Berlin

45. Van Zyl JD, Van Wyk WJ, Heunis CM (1973) The effect of ageing on the mechanical and chemical properties of wood. Paper presented at the IUFRO-5 meeting: wood in the service of man, Pretoria, 22 Sep-12 Oct 1973

46. Yokoyama M, Gril J, Matsuo M, Yano H, Sugiyama J, Clair B, Kubodera S, Mistutani T, Sakamoto M, Ozaki H, Imamura M, Kawai S (2009) Mechanical characteristics of aged Hinoki wood from Japanese historical buildings. CR Phys 10(7):601-611. doi:10.1016/j.crhy.2009.08.009

47. Yokoyama M, Itoh T, Kawai S (2005) Evaluation of the aging of wood: comparison between an accelerated aging treated wood and naturally aged wood. Paper presented at the international symposium on wood science and technology, Yokohama, Japan, 27-30 Nov 2005

48. Yonenobu H, Tsuchikawa S (2003) Near-infrared spectroscopic comparison of antique and modern wood. Appl Spectrosc 57(11):1451-1453 